\title{
Intelektualni kozmos jednog povjesničara. Mikrohistorija u posljednjih četrdeset godina
}

\author{
Pregledni rad \\ Review article
}

UDK 930.2

\begin{abstract}
Cilj ovih stranica, posvećenih metodologiji historiografije jest uvidjeti koliko je konceptualni model mikrohistorijske metodologije utjecao na razvoj historiografske misli u posljednjih četrdeset godina. Nastanak mikrohistorije bio je odgovor na strukturalističku misao, koja je prožela makrohistorijski pristup, prisutan u grupi okupljenoj oko časopisa Annales. Odnos mikro- i makrorazine, odnosno razmjera u historiografiji bio je i ostao poprištem mnogostrukih polemika, a ujedno i poticajno polazište za nova promišljanja povjesničareva zanata.
\end{abstract}

Ključne riječi: Mikrohistorija, makrohistorija, razmjer, paradigma, metodologija

\author{
Ako nam dokumentacija, međutim, \\ pruža mogućnost da rekonstruiramo \\ ne samo nejasne mase \\ nego pojedinačne osobnosti, \\ bilo bi apsurdno odbaciti je
}

(Ginzburg, Sir icrvi)

\begin{abstract}
$\mathrm{K}^{\mathrm{s} a \mathrm{sin}}$ ada je 1976., u izdanju izdavačke kuće Einaudi, Carlo Ginzburg objavio knjigu pod naslovom Il formaggio e i vermi. Il cosmo di un mugnaio del'500 nije ni slutio koliki će odjek knjiga izazvati. Knjiga je u izdanju Grafičkog zavoda Hrvatske 1989. prevedena na hrvatski jezik, pod naslovom Sir i crvi: kozmos jednog mlinara iz 16. stoljeća. Ekscentrična kozmogonija furlanskog mlinara interpretirala se u svjetlu svog specifičnog konteksta, a takav potez omogućio je Ginzburgu da sam odluči o kriterijima prema kojima će ocrtati kontekst unutar kojeg se radnja odvija. Analiza metodologije historije odozdo, o kojoj Ginzburg opširno govori u uvodu, oštra polemika s francuskim povjesničarom Françoisom Furetom i ukazivanje na činjenicu da Menocchio predstavlja sponu pučke i učene kulture, za koje se ranije smatralo kako nisu bile u međusobnoj komunikaciji, učinile su od nje bestseller historiografskog žanra, ali i konceptualni metodološki okvir mnogim budućim istraživačima. Nimalo nevažan element u historiografskim raspravama tih godina, kritika svođenja historiografije na puku naraciju bila je izrazito u opoziciji s dotadašnjom historiografijom. Furet je, suprotno Ginzburgu, odbijao mogućnost da povijesna studija poprimi oblik naracije (Ginzburg 1994: 522). Bila je na pomolu nova historiografska revolucija, koja je svojim intenzitetom bila slabija od one vezane uz časopis Annales. Ginzburg je desetak godina
\end{abstract}


ranije u izradi svoje tesi di perfezionamento ${ }^{1}$ (1964.), pišući o agrarnim kultovima u Friuliju tijekom XVI. i XVII. stoljeća ukazao na razlike između seljačke kulture i dominantne vlasti. Studija je objavljena dvije godine kasnije pod naslovom I Benandanti. U uvodu ove studije pisao je o ponašanjima pojedinaca unutar jednog vrlo ograničenog pogleda, ali i dao kritiku terminima koje su koristili povjesničari okupljeni oko časopisa Annales, a koji su po njegovu mišljenju suviše nejasni poput kolektivnog mentaliteta ili kolektivne psihologije. Citat koji slijedi, kako i ostale tijekom teksta donosim u vlastitom prijevodu.

Proučavao sam u ovoj knjizi vjerska ponašanja i u širem smislu mentalitet seoske zajednice... s jednog vrlo suženog pogleda... Iz pregledane građe proizlazi jedna velika raznolikost individualnih ponašanja. Ukoliko bi se na njima inzistiralo, zapalo bi se u eksces pitoresknosti. Ipak, radije se ušlo u taj rizik, umjesto da se stalno koriste općeniti termini $i$ termini širokog značenja, poput kolektivnog mentaliteta ili kolektivne psihologije (Ginzburg 1966: VII). ${ }^{2}$

Tvrdnje mladog Ginzburga bile su usmjerene na kritiku tadašnje dominantne historiografske misli. Historiografska revolucija koja se dogodila u sklopu izdavanja časopisa Annales u Francuskoj, koji su osnovali Marc Bloch i Lucien Febvre, sve je više dolazila u krizu. Još od Braudelova članka o dugom trajanju u časopisu Annales 1958., istraživanja dugih vremenskih razdoblja, s ciljem istraživanja strukturalnih fenomena, čije se promjene dešavaju u sporom ritmu postala su više pravilo, nego iznimka. $S$ druge strane, serijalna je historija po svojoj prirodi kvantitativna i ne pruža uvid u osnovne probleme s kojima su se pojedinci susretali tijekom prošlosti. Kako bi se u potpunosti realizirao, makrohistorijski je pristup prema Jacquesu Revelu socijalnu historiju pretvorio u svojevrsnu sponu između politike i ekonomije, što se sve više dovodilo u pitanje. Sprega historiografije, politike i ekonomije kompleksno je pitanje. Čini mi se važnim o ovom pitanju prenijeti riječi Revela.

Profesionalni povjesničari nisu jedini korisnici prošlosti - daleko od toga, ne samo sile ili vlasti i institucije, već su i pojedinci stalno u iskušenju da mobiliziraju spoznajne, argumentativne i simboličke resurse prošlosti. Nastavlja Revel: Zapravo, svaki povijesni diskurs podliježe političkim svrhama ili kao posrednik svog autora ili njegove publike ili zato jer često postoji veza među njima... Povjesničari su u prvom redu tih manevara u širokom razmjeru, iz razloga jer stvaraju više ili manje ovlaštene inačice prošlosti, a ponekad to rade za publiku koja je šira od njihovih kolega (Hartog - Revel 2002: 1-3).

Priznavajući iznimnu važnost francuske historiografske revolucije, mikrohistorija pogled odozgo smatra nedovoljno iscrpnim. Sukladno tome, jedan pogled odozdo, sličan onome kakvog je predložio Edward Palmer Thompson (history from below) omogućit će historiografiji otvaranje niza novih pitanja i tema istraživanja. Već je Lawrence Stone ustvrdio propast znanstvene historije poput kliometrije, demografije ili ekonomije i ponudio oživljavanje naracije u svojevrsnoj novoj staroj povijesti (Stone 1979: 3-24).

Usudili bismo se riječima jednog od najznačajnijih hrvatskih povjesničara, Miroslava Bertoše, ocrtati esencijalne odrednice mikrohistorije:

(...) suočitise sesencijalnim odrednicama iminucioznim analizama povijesti svakodnevice, s dramom pojedinačnih i kolektivnih ljudskih sudbina.... (Bertoša 2002: 6).

Prvenstvo oko samog termina mikrohistorija jest nejasno. Ginzburg tvrdi kako je za njega prvi puta čuo 1977. ili 1978. od Giovannija Levija. Dva desetljeća kasnije upustio se u jedno opsežno istraživanje ne bi li uspio pronaći kada se termin mikrohistorija po prvi puta javlja i tko se njime koristio prije negoli ga je talijanska historiografija prisvojila. Termin

Termin tesi di perfezionamento odnosi se na doktorat znanosti, koji izdaje Scuola Normale Superiore iz Pise. Isti je pasus Ginzburgove knjige, ali u druge svrhe koristio i talijanski povjesničar Alessandro Ceccarelli (Ceccarelli 2006). 
mikrohistorija javlja se 1958. u Braudelovom eseju Histoire et sociologie, koji je objavljen u Gurvitchevu Traité de sociologie. Međutim, značenje termina u tom je trenutku sinonim za tradicionalnu povijest događajnice, okrenute velikim ličnostima i epizodama. Godinu dana kasnije istim se terminom u knjizi Picket's Charge. A Microhistory of the Final Attack at Gettysburg, July 3, 1863 koristio američki povjesničar George R. Stewart. Desetljeće nakon Braudela terminom mikrohistorija koristio se meksički povjesničar Luis Gonzales y Gonzales u naslovu monografije Pueblo en vilo. Microhistoria de San Jose de Gracia, u kojem je analizirao promjene u malom selu koji je smatrao tipičnim. Pritom se u značenjskom smislu najviše približio suvremenom značenju tog termina (Ginzburg 1994: 512-513). Mikrohistorija u smislu kakvim se danas definira nastaje sedamdesetih godina XX. stoljeća unutar talijanske historiografije, koja je do tada bila zasnovana na pozitivizmu, Croceovom utjecaju i historicizmu koji je iz njega proizlazilo. Ipak, dobar je dio povjesničara na Apeninskom poluotoku prihvatio tekovine proizašle iz rada grupe povjesničara okupljenih oko časopisa Annales. Nastanak novog historiografskog žanra zahtijevao je ipak mnogo više od puke želje nekolicine tada nepoznatih povjesničara. Institucionalna potpora stigla je iz izdavačke kuće Il Mulino i časopisa Quaderni storici, oko kojeg su se kao ključne figure uredništva okupili Carlo Ginzburg, Carlo Poni, Giovanni Levi i Edoardo Grendi. Upravo će ovaj časopis odigrati ključnu ulogu u širenju mikrohistorije, a njegove će stranice postati poprište, ponekad $i$ žestokih metodoloških rasprava. Nakon što je 1970. postao članom uredništva, Grendi je svojim metodološkim promišljanjem usmjerio rad časopisa u narednim desetljećima, ustvrdivši da će časopis teško moći ponuditi superiornu homogenost doprinosa. Bolji put za afirmaciju bilo je intenzivno iščitavanje izvora, u koncepciji društvenih odnosa shvaćenih kao strukturirane stvarnosti, ali koje bi uvijek ostale vezane uz individualna ponašanja (Caracciolo 1999: 13-29; Palumbo 2004: 11). Ipak, ustvrditi da je časopis Quaderni storici svojevrsni manifest mikrohistorije bilo bi i suviše pretenciozno. Ne postoji mikrohistorijska škola, ne postoji ni jedinstvena metodologija. Suprotno tome, postoji jak otpor prema stvaranju jasnog referentnog metodološkog okvira. Mikrohistorija se prema tome veže uz radne procedure svakog povjesničara pojedinačno. Već je Mirjana Gross, vrsna pratiteljica suvremenih metodoloških kretanja pokušala definirati jesu li mikro- i makrorazina unutar historiografije kompatibilni ili ne. Valja ponoviti njezine riječi da je mikrohistorija odgovor na svojevrsnu krizu društvenih znanosti, a predstavlja i naglašeni otpor prema shvaćanju historiografije kao jedino retoričke ili estetičke produkcije. Mikrohistorija bi se svakako mogla definirati kao kritika i dopuna makrohistoriji, zasnovana na empiričkim temeljima. Pokazuje, priznajući njenu vrijednost, jako nepovjerenje prema upotrebi serijalne historije (Gross 1994: 19).

Odnos historije, retorike i dokaza (arhivskih materijala) često je krivo shvaćan. Bliskost historije i retorike dovela je odnos povijesti i dokaza na samu marginu. Tvrdi Ginzburg:

Ideja da povjesničari trebaju ili mogu potvrditi bilo što čini se mnogima zastarjela, ako ne čak i smiješna. Čak i oni koji manifestiraju nelagodu prema intelektualnoj klimi koja je dominantna, uzimaju gotovo uvijek zdravo za gotovo da se retorika i dokaz međusobno isključuju. U ovoj knjizi pokazujem kako a) je u prošlosti dokaz smatran sastavnim dijelom retorike b) ta očiglednost koja je danas zaboravljena implicira sliku rada povjesničara, uključujući i suvremene povjesničare, koja je mnogo realističnija i kompleksnija od one koja je danas u modi (Ginzburg 2001: 13).

U mikrohistorijskim studijama svaki se događaj ili ličnost pozicionira na nekoliko razina, između mikro- i makrorazine. Ne postoji jasna opozicija između lokalne i globalne povijesti, jednako tako nema opozicije između kvantitativnih i kvalitativnih metoda. U radu mikropovjesničara vidljiv je poticaj za povratak naraciji. Povjesničari se okreću malim stvarima koje proizlaze iz izvora, i na taj način historija postaje konkretnija od tradicionalnih 
društvenih studija (Szijártó 2002: 210). Ipak, svođenje mikrohistorije na jednostavno smanjivanje vremenskog i geografskog razmjera ne nudi cjelokupno objašnjenje. Ovako pojednostavljena definicija dala bi školsku definiciju za lokalnu historiju. Mikrohistorija odbija tvrdnju da postoji jedinstven i homogeniziran kontekst. Levi nudi inverzivni proces, $u$ kojem bi se od mikrorazine prešlo na makrorazinu, a ne obrnuto. Ne sagledava se kontekst koji utječe na pojedinca, upravo suprotno, svaki pojedinac stvara bar jedan kontekst ili više njih koji ga okružuju. Konceptualni mikroskop na ovaj način postaje iznimno važan i moćan instrument istraživanja. Mijenjanje širine pogleda (nužno) znači i mijenjanje sadržaja koji se iz izvora iščitava (Revel 1994: 554). Blochov model ponudio je da se historiografija shvaća kao konstrukcija, sastavljanje fragmenata, s ciljem stvaranja uvjerljive priče, što su mikropovjesničari prihvatili, ipak i takva je priča samo rekonstrukcija (Ginzburg - Gundersen 2003: 8). Dakako da nova metodologija nije nastala ni iz čega, vrlo je jak utjecaj na mikropovjesničare izvršila antropologija. Grendi je smatrao kako je terenski rad povjesničara prekratak, kako su dokumentarne serije arhivskih izvora često manjkave, naglašavajući da se ostale društvene znanosti ne razlikuju od antropologije toliko metodologijom, koliko holističkom intenzivnošću kojom pristupaju analizi ljudskih obrazaca ponašanja (Grendi 1977: 510). Antropologija Clifforda Geertza, osobito njegova praksa gustog opisa, s ciljem naglašavanja uloge pojedinaca ili događaja koji se smatraju ključnima, želi dati znanstvenu relevantnost bez potrebe stvaranja kontekstualizacija ili apstraktnih sistematizacija. Moguće je tako rekonstruirati društveni ili kulturalni kontekst koji je na njih utjecao (Geertz 1973: 3-30). Prema Geertzu analiza započinje nizom značajnih znakova (simbola) koje je potrebno smjestiti u jednu razumsku strukturu. Levi smatra kako iz Geertza proizlazi kulturna historija bez društvene analize ili društvena analiza stereotipa, koja je lišena rekontekstualizacije društvenih procesa (Levi 1993). Također, polazeći od The Great Cat Massacre and Other Episods in French Cultural History Roberta Darntona, Geertzovog kolege i suradnika sa sveučilišta Princeton, oštro je kritizirao Geertzovu praksu gustog opisa. Metodologija se zasniva na istraživanju kultura i nalazi se u kontrapoziciji spram kvantitativne i kvalitativne historije. Smatrajući da se historija ne smije svoditi na puku antropološku analizu usmjerenu na potragu za mrežom značenja kojima je protkana kultura, Levi je ustvrdio kako povjesničar mora napraviti korak dalje (Levi 1985a: 269-276). Ginzburg u knjizi Il filo e le tracce. Vero, falso, finto, u poglavlju pod naslovom L'inquisitore come antropologo priznaje kako je čitajući arhivske izvore imao osjećaj da stoji iza inkvizicijskih sudaca i prati njihove poteze, čekajući ne bi li optuženi počeli pričati o svojim vjerovanjima (Ginzburg 2006: 270-280). Svakako da su, bez obzira na različite metodologije i vrstu izvora koje koriste, historiografija i antropologija usko povezane znanosti. Njihova je isprepletenost dovela do otvaranja niza novih pitanja u historiografiji, a ujedno obogatila obje discipline.

Čitajući zbirku dijaloga Vittoria Foe i Ginzburga, naišao sam na citat koji donosim, a koji zorno prikazuje da su mikrohistoriju promišljali ne samo profesionalni povjesničari, već i intelektualci drugih grana znanosti. Zapisao je Foa u uvodu svoje knjige Per una storia del movimento operaio.

Radi se o novoj društvenoj historiji, ne kao historiji koja bi se bavila materijalnim stanjem, nego historiji kulture, koja otkriva dublje i kompleksnije motivacije. Britanski su povjesničari, što se tiče povijesti radničkog pokreta u posljednjih petnaestak godina otvorili taj put samo u manjoj mjeri. Dolazi do toga da se vrlo lako odbacuje ideologija i vrednuje povijesni proces kao sam sebi svrhom. U odnosu na jedan nacrt ili sudbinu koja je prethodno utvrđena i takav Napredak treba dovesti do razdvajanja istraživanja i pripovijedanja, ponovnom vrednovanju detalja $i$ to ne samo zato jer je detalj sam u sebi lijep, nego zato jer se preko njega dolazi do važnijih stvari koje su do sada bile nepoznate ili zapostavljane. Ponovno uroniti temelje inteligencije u svoj kompleksnosti stvarnosti i ponovno otkriti pojedinca u povijesti. Prisilan 
je to prijelaz, neophodan kako bi se došlo do novih sinteza povezanih s pokretom, a ne ideologijom (Foa - Ginzburg 2003: 136).

Začetke mikrohistorije dugujemo i općenitom raspoloženju koje je u Europi bilo prisutno nakon 1968. Napredak više nije bio siguran u onolikoj mjeri kao prije, vremena su bila nesigurna, a budućnost nepredvidljiva.

Ono što su ljudi sad tražili od historije nisu više bile lekcije, učenje iz prošlosti ili načini shvaćanja sadašnjosti, nego mjesto gdje se skloniti od nesigurnih trenutaka (Revel 1995: 34).

Unutar novog okvira odbacivao se relativizam i iracionalizam, svođenje historiografije na čisto retoričku razinu interpretacije izvora, a ne događaja. Historija bi imala prema Leviju zadaću da pronađe ogledne primjere, koji bi omogućili pojednostavljenje generalnih koncepata. Zajedničko svim mikrohistorijskim studijama bilo bi intenzivno, mikroskopsko iščitavanje izvora, s ciljem dobivanja vrlo detaljne slike svih pojedinosti koje izvori u sebi sadrže i koja bi ukazivala na procese koji su najčešće ostajali nezapaženi istraživanjima u većem razmjeru. Odustaje se od stvaranja čvrstih modela koji bi bili regulirani čvrstim zakonima funkcioniranja. Smatra se da se preko pripovijedanja o konkretnim događajima teži objasniti funkcioniranje društva, koje bi generalizacijama bilo izobličeno. Važna karakteristika je i ta da mikropovjesničari navode tijek radnih procedura, nedostatke $u$ arhivskoj građi i tehnike interpretacije kao sastavni dio narativa (Levi 1993: 54-55). Mikrohistorija ne žrtvuje pojedinačne događaje zbog generalizacije! Mikropovjesničari se odmiču od dijakronijskog, da bi više pažnje posvetili sinkronijskom pristupu. Osnovno je pitanje bilo koliko život sela, pojedine zajednice ili pojedinca u kratkom trajanju može biti značajan za širi kontekst povijesnih zbivanja. Ipak, postoji ono što Grendi naziva jednim vrlo efikasnim oksimoronom, ujedno i epistemološkim lomom eccezionale normale ili iznimnom normalnošću (Grendi 1977: 512). Smatrao je u eseju, koji je objavljen 1986. u časopisu Quaderni storici pod naslovom La pratica dei confini: Mioglia contro Sassello, 1715-1754, kako spor dvaju feuda Mioglie i Sassella omogućuje da shvatimo kako se poimanje granica promijenilo od prve polovice XIX. stoljeća do danas. Mioglia i Sassello vodili su dugotrajan spor oko granica koje su ih razdvajale, što je dovelo do višegodišnje političke krize. Grendi je $u$ istraživanju konflikta između dva sela napustio koncept termina granice, koji smatra vojnim terminom nastalim u XIX. stoljeću. Naime, granice u modernom smislu riječi nastaju radom kartografa, pregovarača i predstavljaju svojevrsnu materijalizaciju nečeg što je nekada imalo više ubicirajući smisao i bilo povezano uz pojam posjedovanja i vršenja laičke i crkvene moći (Grendi 1986: 811-846). Ovim je primjerom Grendi uspio dokazati da ponekad treba napustiti čvrste uzde kategorija, koje onemogućavaju da se sagleda svaki pojedini aspekt prošlih zbivanja.

$\mathrm{U}$ jednome od esencijalnih radova o mikrohistoriji pod naslovom II nome e il come. Scambio ineguale e mercato storiografico, Ginzburg i Poni dali su kritiku na položaj talijanske historiografije spram francuske. Odnos u kojem su, usprkos iznimno bogatoj ostavštini arhivskih izvora povjesničari bili vezani za metodološke modele uvezene iz Francuske. Otišli su i korak dalje, ponudili su da se od imena, kao osnovnog obilježja svakog pojedinca učini osnova za povijesna istraživanja. Tvrdili su kako sve veći uspjeh mikrohistorijskih studija valja pripisati mnogim čimbenicima, napose društvenim promjenama, ali i naprednim organizacijama rada i ekipama stručnjaka koje su potrebne za makrohistorijske studije (Ginzburg - Poni 1979: 181-190).

Mikrohistorija bi mogla biti definirana kao paradigma indiziario, s hipotetičkim ciljem da se organiziraju ne samo poznati elementi, već i oni koji slijede i još su uvijek nepoznati. ${ }^{3}$

\footnotetext{
U eseju Spie. Radici di un paradigma indiziario predložen je metodološki model prema kojem je moguće uvidjeti sličnosti između polja znanja koja su vrlo različita među sobom, ali spojena sličnom metodološkom procedurom (Ginzburg 1979: 57-106).
} 
Ginzburg tvrdi da je znanje povjesničara poput onoga u medicini indirektno, vjerojatno (nesigurno) i u tragovima, a ako je prošlost zamagljena, postoje špijuni i korijenje koji ju razotkrivaju (Ginzburg 1979: 57-106). Preko svog paradigma indiziario pokazao je da se osim mjerljivim opažanjima, nepoznati događaji mogu identificirati i preko naizgled beznačajnih znakova. Čak i najgorljiviji protivnici ovakve tvrdnje bit će prisiljeni prihvatiti kako povijesni izvori obiluju takvim beznačajnim znakovima, tragovima, koji poput špijuna mogu povjesničara navesti na konkretne zaključke. Svaki seljak, pojedinac koji kupuje žito, pšenicu ili manufakturne proizvode sudjeluje i doprinosi u svjetskom sistemu ekonomije, mlinar koji stvara kozmogoniju samo je ogledni primjer mentaliteta ljudi i imaginarija o stvaranju svijeta, lokalni moćnik bez materijalnih bogatstava, koji raspolaže jedino društvenom moći morao je zasigurno biti široko rasprostranjen model društvenih ponašanja u Europi Ancien režima! Odluke pojedinaca, grada ili zajednice odnose se tako na širi kontekst. Stoga, ne mogu i ne smiju biti promatrane jedino kao izolirane pojave. Levi je to pokazao u kapitalnom djelu L'eredità immateriale, opisujući ekonomske prilike, trgovinu zemljom, obiteljske odnose i strategije krajem XVII. stoljeća u selu Santena, smještenom u pokrajini Pijemont. Život sela odvijao se oko djelatnosti lokalnog egzorcista Giovanija Battista Chiese, koji nije imao materijalnih bogatstava, dobivao je i trošio nematerijalno nasljedstvo, sačinjeno od društvene moći. Levi je ponudio alternativni model shvaćanja društvenih akcija, prema kojoj je svaka od njih viđena kao osobno trgovanje, manipulacija, izbor ili odluka u obliku normativnih stvarnosti, koje iako su sveprisutne, ipak nude mogućnost vlastitih izbora i sloboda (Levi 1993: 47-65). U funkcioniranju Santene vidljiv je način na koji se Chiesa svojim djelovanjem uklopio u promjene svog vremena, prema kojima se plemićke titule nisu nužno poklapale s materijalnim bogatstvom, a rodbinske veze nisu imale utjecaj na svakodnevni život. Unutar jednog rigidnog društvenog sistema, Chiesa je imao prostora za vlastite izbore i postupke. Jednom riječju, unutar sistema stvarao je svojim postupcima kontekst unutar kojeg je djelovao i živio. Vidljivo je da se uključivanje pojedinca pripadnika jedne klase u klasu koja bi za njega bila karakteristična ne vrši samo po aspektima koji su im zajednički. Potrebno je analogno analizirati sličnosti i razlike. Kontekst unutar kojeg se Chiesa identificira ne sastoji se samo od sveukupnosti koju dijeli s njemu sličnima, ono je identifikacija područja sličnosti, između sistema odnosa u kojem su različite stvari ukomponirane (Levi 1985; Mastrogregori 2003). Glavni lik ove studije prisutan je u različitim kontekstima i na različitim razinama, koje idu od lokalnog do globalnog. Citirat ću poduži pasus Massima Mastrogregorija kako bi čitatelju približio visoku razinu eksperimentalnosti mikrohistorije.

Svaki povijesni lik, tvrdi Lepetit u jednom eseju o mikrohistoriji, koristeći se učenjem norveškog antropologa Frederika Bartha ima vlastiti „prostor društvenog iskustva", koji s drugima tvori mrežu. Povijesno opažanje cilja definiranju razmjera takvog iskustva. Svaki povijesni lik ima različite resurse i može djelovati u poljima različite rasprostranjenosti. Pažljivo razmatranje tih varijacija razmjera iskustva povijesnih likova služi identificiranju sistema konteksta u kojima se upisuju društvene igre. Ambicija te dinamične kartografije koja je pravi eksperimentalni dio istraživanja ... je ta da se pronađe i ocrta u svojim varijetetima jedan skup karata koje odgovaraju jednako tolikim društvenim područjima. Eksperiment povjesničara pokušava tako razriješiti, dajući joj u isto vrijeme jedan oblik, napetost između razmjera rekonstrukcije i razmjera iskustva aktivnih sudionika povijesti. Iskustvo nad izvorima susreće tako iskustvo proživljenog (Mastrogregori 2003: 10).

U Levijevoj studiji o Santeni svaka se društvena akcija smješta na više razina, razmjeri se neprestano isprepliću, a povijesni se akteri smještaju u različite društvene kontekste. Možda je upravo ova pozicija eksperimentalnosti najveće nematerijalno nasljedstvo ove znamenite studije! Odavno je ustanovljeno da povijest treba temeljiti na dokumentima, ali ona u njima ne stoji. Arhivski dokumenti su uvijek manjkavi, iako naočigled iscrpni, stoga je 
svaka rekonstrukcija, usprkos iznimnoj minucioznosti i intenzivnosti kojom se pristupa građi samo fragment povijesne zbilje. Nije dovoljno interpretirati samo ono što se izričito navodi u izvorima, već i ono što izvori skrivaju. Metoda detaljnog iščitavanja je stoga neophodna, a povjesničarev posao nije skupljati podatke, nego in interpretirati (Fonseca - Sivo 2000: 555). Dobar dio mikropovjesničara okrenuo se kulturalnim studijama. Natalie Zemon Davies, Darnton, Emmanuel Le Roy Ladurie i Ginzburg samo su najpoznatija imena povjesničara okrenutih istraživanjima povijesti kulture. Opozicija ovoj grupi izrazito sklonoj istraživanju kulturalne problematike, su ne manje važne studije društveno-ekonomskog karaktera, poput onih Levija i Grendija. Čini mi se važno prenijeti riječi Maurizija Gribaudija, koji je na znanstvenom skupu u Veneciji povodom dvadeset i pete godišnjice izlaženja Levijeve studije L'eredità immateriale, naglasio da mikropovjesničari sedamdesetih nisu samo kritizirali konzervativnu historiju, već su željeli osvijetliti teoretske postavke ljevice, koja je implicitno prihvatila jedan niz prikaza stvarnosti i hijerarhija relevantnosti ekonomskog tipa, koje su po svojim postavkama bile konzervativne. Najjača je kritika mikrohistoriji, tvrdi Gribaudi, dolazila od povjesničara suvremenog doba koji su u njoj vidjeli kritiku marksističkih modela kojima su bili privrženi (Gribaudi 2011: 11). Mikrohistorija nije nastala u okrilju grupe povjesničara okupljenih oko časopisa Annales ili nove povijesti, ali je svojim metodološkim postavkama obogatila raznolikost njihovih paradigmi. Jedna od mogućih definicija historije bila bi: disciplina koja generalizira svoja pitanja, pitanja generalnog značaja i pritom priznaje kako bi odgovori na ta pitanja bili neograničeni, što bi dovelo do priznanja da oni ovise o lokalnim kontekstima (Trivellato 2011: III). Promišljajući mikrohistoriju, smatram kako poduke Blocha, Grendija, Levija, Ginzburga... ostaju u svojoj metodološkoj formi svježe i u desetljećima od njihova nastanka.

\section{POPIS LITERATURE}

\section{BERTOŠA 1995}

Miroslav Bertoša, „Istra: Doba Venecije (XVI.XVIII. st.)“, u: Povijest Istre, 2, Pula 1995.

\section{BERTOŠA 2002}

Miroslav Bertoša, Izazovi povijesnog zanata: lokalna povijest i sveopći modeli, Zagreb 2002.

\section{CARACCIOLO 1999}

Alberto Caracciolo, „La prima generazione“, Quaderni storici, 100, Bologna 1999., 13-29.

\section{CECCARELLI 2006}

Alessandro Ceccarelli, Contesto e concetto. Alcune riflessioni sulla microstoria, 2006., http://archiviomarini.sp.unipi.it/77/ (21. siječanj 2014.).

\section{FOA - GINZBURG 2003}

Vittorio Foa - Carlo Ginzburg, Un dialogo, Milano 2003.

\section{FONSECA - SIVO 2000}

Cosimo Damiano Fonseca - Vito Sivo, Studi in onore di Giosue Musca, Bari 2000.

\section{GEERTZ 1973}

Clifford Geertz, „Thick Description: Toward an Interpretive Theory of Culture", u: The Interpretation of Cultures: Selected Essays, New York 1973., 3-30.

\section{GINZBURG 1966}

Carlo Ginzburg, I benandanti. Stregoneria e culti agrari tra Cinquecento e Seicento, Torino 1966.

\section{GINZBURG 1976}

Carlo Ginzburg, Il formaggio e i vermi. II cosmo di un mugnaio del'500, Torino 1976.

\section{GINZBURG 1979}

Carlo Ginzburg, „Spie. Radici di un paradigma indiziario", u: Crisi della ragione. Nuovi modelli nel rapporto tra sapere e attività umane, (ur: Aldo Gargani), Torino 1979., 57-106.

\section{GINZBURG 1989}

Carlo Ginzburg, Sir i crvi: kozmos jednog mlinara iz 16. stoljeća, Grafički zavod Hrvatske, Zagreb 1989. 


\section{GINZBURG 1994}

Carlo Ginzburg, „Microstoria: due o tre cose che so di lei", Quaderni storici, 86, Bologna 1994., 511-539.

\section{GINZBURG 2001}

Carlo Ginzburg, Rapporti di forza. Storia, retorica, prova, Milano 2001.

\section{GINZBURG 2006}

Carlo Ginzburg, Il filo e le tracce. Vero, falso, finto, Milano 2006.

\section{GINZBURG 2010}

Carlo Ginzburg, Premio Balzan 2010 per la storia d'Europa (1400-1700), 2010., http://www. balzan.org/upload/estrattoginzburgita.pdf (21. siječanj 2014.).

\section{GINZBURG - PONI 1979}

Carlo Ginzburg - Carlo Poni, „Il nome e il come: scambio ineguale e mercato storiografico", Quaderni storici, 40, Bologna 1979., 181-190.

\section{GINZBURG - GUNDERSEN 2003}

Carlo Ginzburg - Trygve Riiser Gundersen, "On the dark side of history", Eurozine, 2003., http://www.eurozine.com/articles/2003-0711-ginzburg-en.html (21. siječanj 2014.).

\section{GRENDI 1977}

Edoardo Grendi, „Microanalisi e storia sociale“, Quaderni storici, 35, Bologna 1977., 506-520.

\section{GRENDI 1986}

Edoardo Grendi, „La pratica dei confini: Mioglia contro Sassello, 1715-1754“, Quaderni storici, 63, Bologna 1986., 811-846.

\section{GRIBAUDI 2011}

Maurizio Gribaudi, „La lunga marcia della microstoria. Dalla politica all'estetica", u: $A$ venticinque anni da L'eredita immateriale, (ur: Paola Lanaro), Roma 2011., 9-23.

\section{GROSS 1994}

Mirjana Gross, „Mikrohistorija dopuna ili suprotnost makrohistorije", OTIVM, 2, Zagreb 1994., 18-36.

\section{HARTOG - REVEL 2002}

François Hartog - Jacques Revel, „Historians and the Present Conjuncture", u: Political Uses oft he Past. The Recent Mediterranean Experience, (ur: Jacques Revel - Giovanni Levi), London 2002., 1-12.

\section{LEVI 1985}

Giovanni Levi, L'eredità immateriale. Carriera di un esorcista nel Piemonte del seicento, Torino 1985.

\section{LEVI 1985A}

Giovanni Levi, „I pericoli del geertzismo“, Quaderni storici, 58, Bologna 1985., 269-276.

\section{LEVI 1993}

Giovanni Levi, „Un dubbio senza fine non è un dubbio. A proposito di microstoria“, u: Storia locale e microstoria: Due visioni in confronto, (ur: Joseba Agirreazkuenaga et al.), Bilbao 1993., 47-65.

\section{MASTROGREGORI 2003}

Massimo Mastrogregori, „L'idea della storia sperimentale", Belfagor, 58, Firenze 2003., 1-18.

\section{MOMIGLIANO 1977}

Arnaldo Momigliano, „Linee per una valutazione della storiografia del quindicennio 19611976", Rivista storica italiana, 89, Napoli $1977 .$, 596-609.

\section{MUIR 1991}

Edward Muir, „Introduction: Observing Trifles", $\mathrm{u}$ : Microhistory and the Lost Peoples of Europe, (ur: Edward Muir - Guido Ruggiero), Baltimore 1991., VII-XVIII.

\section{PALUMBO 2004}

Paolo Palumbo, „Le dialettiche della microstoria. Edoardo Grendi e l'interdisciplinarità nel mestiere dello storico", Balbisei. Ricerche Storiche Genovesi, Rivista digitale a cura del Dipartimento di storia moderna e contemporanea dell'Università degli Studi di Genova, Genova 2004., http://www.balbisei.unige.it/numero0. pdf (21. siječanj 2014.). 


\section{REVEL 1994}

Jacques Revel, „Microanalisi e costruzione del sociale", Quaderni storici, 86, Bologna 1994., 549-575.

\section{HUNT - REVEL 1995}

Lynn Hunt - Jacques Revel, Histories: French Constructions of the Past, New York 1995.

\section{STONE 1979}

Lawrence Stone, „The Revival of Narrative: Reflections on the New Old History", Past and Present, 58, Oxford 1979., 3-24.

\section{SZIJÁRTÓ 2002}

István M. Szijártó, „Four Arguments for Microhistory“, Rethinking History, 6, London 2002., 209-215.

\section{TRIVELLATO 2011}

Francesca Trivellato, „Is There a Future for Italian Microhistory in the Age of Global History?", California Italian Studies, 2, 2011., http://escholarship.org/uc/item/0z94n9hq (21. siječanj 2014.).

\section{SAŽETAK}

Razvoj historiografske misli doživio je u posljednje vrijeme značajne promjene. Nekada futuristička i napredna historiografija vezana uz časopis Annales danas nosi naziv normalne paradigme. Rađanje novih pogleda na historiografiju ukazuje kako je zanat povjesničara evoluirao u posljednjih nekoliko desetljeća. Značaj je mikrohistorije u pomicanju granica zanata povjesničara neosporan. Ona je bila i ostala samo jedna, vrlo vjerojatno najuspješnija od mogućnosti zamjene stare paradigme. Evolucijski slijed mikrohistorije i njena prihvaćenost diljem svijeta učinili su ju normalnom znanošću i najrasprostranjenijom metodologijom u većem dijelu historiografija. Pitanje razmjera, koje je u historiografiji često postavljano, čini mi se u eri globalne historije značajnim. Igra razmjera postala je u posljednjih četrdesetak godina tema oko koje su se vodile oštre rasprave. Kome u doba globalizacije treba historiografija koja se bavi minucioznim analizama pojedinih događaja, tvrdili su skeptici ove metodologije. Odgovor leži prije svega u iznimnoj konceptualnoj snazi koje pruža takva historiografija, u njenoj moći da od mikro- prijeđe na makrorazinu. Svakako mikrohistoriju, ne možemo definirati prema mikrokozmosima koje istražuje. Mikropovjesničari stoga istražuju lokalnu povijest od globalnog značaja.

\section{RIASSUNTO}

\section{Il cosmo intelettuale di uno storico. La microstoria negli ultimi quaranta anni}

L'evolversi del pensiero storiografico ha subìto negli ultimi tempi cambiamenti notevoli: da una parte la storiografia delle Annales, un tempo all'avanguardia, ha finito col convertirsi essa stessa in un paradigma classico; dall'altra l'evolversi di nuovi approcci storiografici ha mostrato quanto sensibilmente il mestiere dello storico si sia evoluto negli ultimi decenni. L'importanza della microstoria nell'ampliamento delle frontiere dello storico è, sotto questo aspetto, emblematica. La microstoria è solo la pratica più riuscita (o una delle più riuscite) per la sostituzione del vecchio paradigma.

Il paradigma microstorico accettato da gran parte delle storiografie, fà di essa probabilmente una scienza normale e una delle metodologie più usate nel paesaggio storiografico degli ultimi decenni. 
Credo che la questione della riduzione di scala, cioè dell'intreccio tra 'micro' e 'macro', che spesso viene sollevata nell'ambito storiografico, sia una istanza di grande importanza nell'era della storia globale. I critici hanno infatti spesso chiesto a che cosa serva studiare eventi singoli, sottoponendo materiale archivistico ad analisi "microscopiche", in un periodo di globalizzazione generale. La risposta più ovvia sta nel potere concettualizzante di questa storiografia e nella sua capacità di salire o scendere di scala nell'analisi. Quel che è certo, comunque, è che la microstoria non può essere definita solo in base ai microcosmi che studia: essa si occupa sì di storia locale, ma di rilevanza globale.

Parole chiave: Microstoria, macrostoria, scala, paradigma, metodologia 